\title{
Bronchial fistula closure with negative pressure wound therapy: a feasible and cost-effective treatment
}

\section{Fechamento de fístula brônquica com uso da terapia por pressão negativa: um tratamento viável e custo-efetivo}

Rodrigo Barboza Nunes', Bruno Francisco Müller Neto', Federico Enrique Garcia Cipriano², Pedro Soler Coltro1, Jayme Adriano FARINA JÚNIOR'.

\begin{abstract}
A B S T R A C T
Treatment of bronchial fistula (BF) after pulmonary lobectomy is a challenge. Often, patients require long hospital stay, have recurrent empyema and pneumonia, are susceptible to sepsis, often need broad-spectrum antibiotics, as well as various surgical approaches. With the advent and growing evidence of the benefits of negative pressure therapy (NPT), its use in some patients with BF has been reported with encouraging results concerning its feasibility and cost-effectiveness. The aim of this study was to demonstrate the application of NPT as a resource for BF treatment and comparatively analyze the overall cost of treatment.
\end{abstract}

Keywords: Bronchial Fistula. Pneumonectomy. Negative Pressure Wound Therapy. Cost-Benefit Analysis.

\section{INTRODUCTION}

B ronchial fistula can occur as a complication of pulmonary infectious diseases, after thoracic trauma, consequent to invasive thoracic procedures and most commonly as a complication of pulmonary surgical procedures'. Studies show variable incidence of this complication secondary to thoracic surgery, occurring in frequency ranging from $4.5 \%$ to $20 \%$ of patients after pneumonectomy and about $1 \%$ after lobectomy. Mortality rates vary from $18 \%$ to $67 \%{ }^{1}$.

Patients with this condition usually require a long period of hospitalization, often being colonized by hospital germs, presenting empyema relapses, possible evolution to sepsis, need of broad-spectrum antibiotics, as well as various surgical approaches.

Negative pressure therapy has been used as an important alternative adjuvant in the treatment of complex wounds of various etiologies, with much evidence of its benefits in the literature ${ }^{2,3}$. There are even some successful treatment reports of patients with BF who used NPT ${ }^{4}$. The purpose of this study is to demonstrate the application of NPT as a therapeutic resource for BF and comparatively analyze the overall treatment cost.

\section{TECHNICAL REPORT}

A patient with BF communicating with thoracostomy was treated with NPT at the Hospital das Clínicas of the Faculdade de Medicina de Ribeirão Preto, Universidade de São Paulo (HCFMRP-USP). Previously, this patient had undergone several surgeries to treat complications such as empyema and to attempt BF closure, without success.

In 2008, this male, 50-year-old patient was diagnosed with pulmonary cystic bronchiectasis in the lower right lobe, being treated by lobectomy of this segment by the Thoracic Surgery team. After the initial procedure, the patient developed several complications and required 13 other surgeries between 2008 and 2013. In October 11, 2013, the Plastic Surgery team introduced the NPT in the pleurostomy wound (Figures 1A and 1B) in a way that a piece of the polyurethane foam (Figure 1C) was adapted to be introduced into the pleural cavity, the other part remaining on the chest skin for

1 - Division of Plastic Surgery, Clinics Hospital, Ribeirão Preto Medical School, University of Sao Paulo. 2 - Division of Thoracic and Cardiovascular Surgery, Clinics Hospital, Ribeirão Preto Medical School, University of Sao Paulo. 

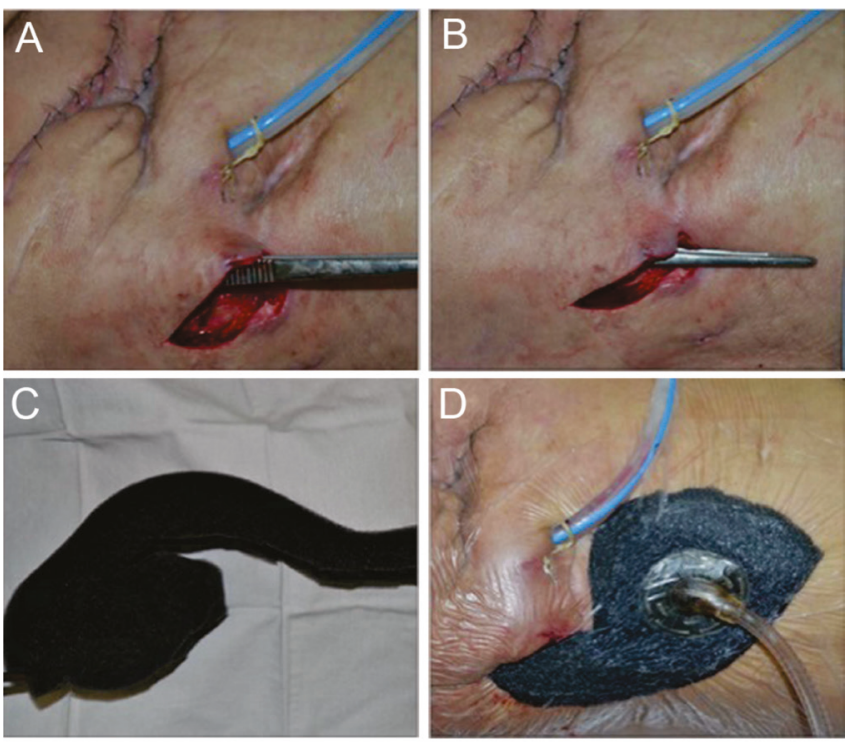

Figure 1. Application of NPT. (A): Wound of thoracostomy and chest drainage. Tweezers partially introduced in the pleurostomy cavity. (B) Tweezers introduced at the site of thoracostomy showing the depth of the pleural cavity. (C) Cut of the polyurethane foam to be introduced into the pleural cavity. (D): Foam partially inserted into the pleural cavity and the dressing with the NPT operating under continuous regimen of $125 \mathrm{mmHg}$.

bonding with the suction tube (Figure 1D). The thoracic cavity and the remaining lung parenchyma can be seen in the CT scan image in Figure 2A. In total, there were six exchanges of the dressing, guided by the evolution of the wound, every 5 days on average, until November 13, 2013, when we discontinued NPT after evidence of BF occlusion.

The study also compared surgical hospital costs with hospital procedures and costs involved after the NPT start. These data were obtained from the Cost Section of the HCFMRP-USP Technical Advisory. The calculation of the costs of surgical and anesthetic procedures and hospital admissions was based on the average hourly values per procedure and average daily values, respectively, for the year 2014.

With the use of NPT, there was contraction of the pleurostomy cavity and occlusion of the bronchial tree fistula in the period of 1 month. This result was documented by the control tomography (Figure 2).

Hospital costs with surgery and anesthesia in the 13 procedures performed to treat complications prior to NPT use were $R \$ 28,825.35$. Moreover, to calculate the total expenditure, we must add the hospitalization costs. The patient remained about eight months hospitalized to treat complications, totaling $R \$ 141,199.12$. Therefore, spending on surgical procedures, anesthesia and hospitalization for the treatment of this patient's complications prior to NPT use totaled $\mathrm{R} \$ 170,024.47$.

After the introduction of NPT, expenses including surgery, anesthesia, hospitalization and dressings were $R \$ 26,162.70$. Thus, the costs of NPT use for the treatment of this patient's bronchial fistula was 6.5 times lower than in the previously used conventional treatment.

We discharged the patient at the end of treatment. During the following 22 months after the end of NPT, the patient had no complications, either pulmonary or related to the surgical procedures, and required no new admissions. The wounds remain healed (Figure 3), with significant improvement in quality of life.

\section{DISCUSSION}

The scientific literature has pointed out several NPT advantages on various types of wounds, including in the thoracic cavity. The use of NPT helps in the treatment of postoperative complications that are difficult to resolve, such as bronchial fistula and empyema ${ }^{6}$.

There are few reports about the auxiliary role of NPT in BF closure. An article suggests that the use of NPT promotes the closing of small caliber BF (diameter below $8 \mathrm{~mm})^{7}$. However, the application of NPT must be performed by experienced staff, as it can present serious

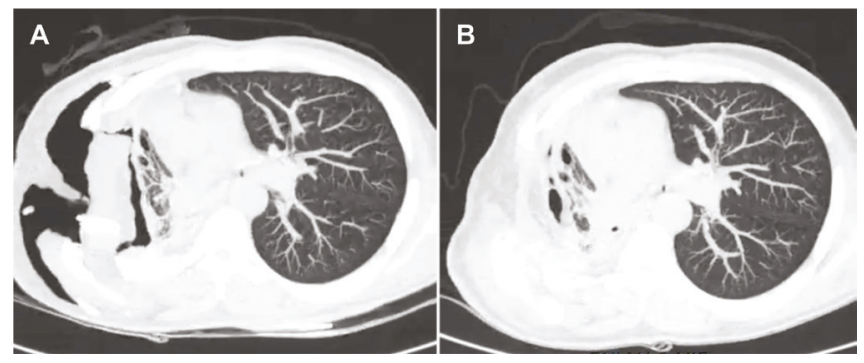

Figure 2. Comparison of computed tomography images. (A): image before NPT, showing the thoracostomy thoracic cavity and the right lung remaining parenchyma. (B): image after completion of NPT with, showing obliteration of the right thoracostomy cavity and closure of the bronchial fistula. 


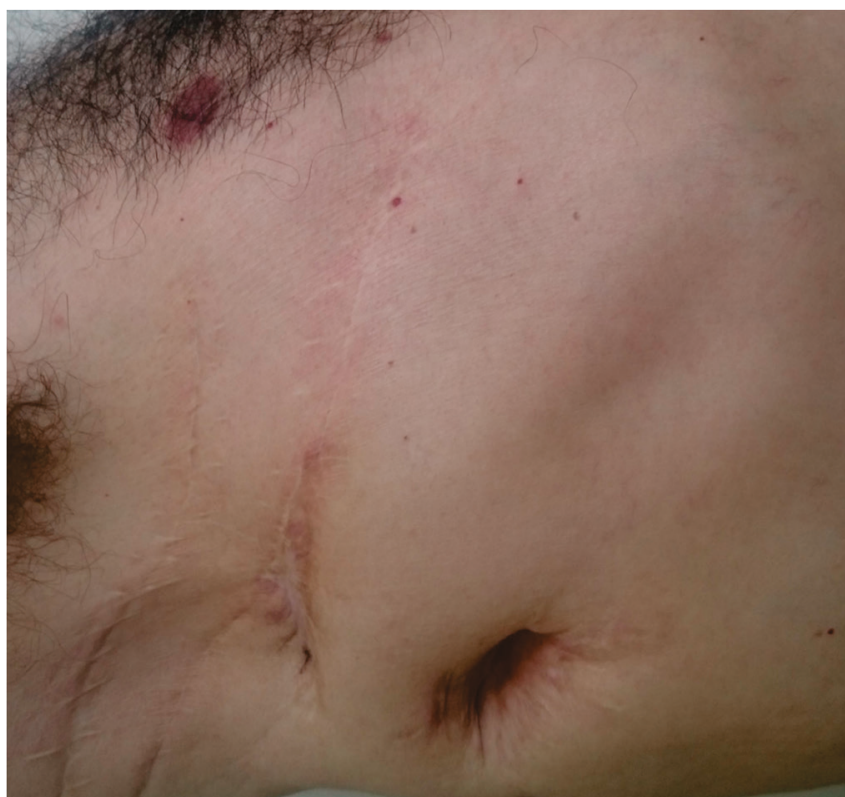

Figure 3. Anterolateral aspect of the patient's right chest, 22 months after the end of NPT, with healed wounds. risks. There are reports of life-threatening complications such as right ventricular or aortic rupture ${ }^{8}$. In our patient, the lung and chest wall architectures were already changed, with fibrosis and retractions resulting from the numerous performed procedures. The application of NPT did not bring any harm to the patient.

We found no reports in the literature comparing the costs of the therapies used in the management of bronchial fistula, but some authors suggest applying NPT early in lung complications such as empyema and for chest wound closure 4 . In this patient, we showed that the cost of treating the fistula bronchial after the introduction of NPT was 6.5 times lower than the cost of the conventional, previously undergone treatments.

Finally, we can conclude that NPT is a viable and cost-effective option for the closure of bronchial fistula after pulmonary lobectomy.

\section{R E S U M O}

O tratamento de fístula brônquica (FB) após lobectomia pulmonar é um desafio. Muitas vezes, o paciente demanda longo tempo de internação, apresenta recidivas de empiema e pneumonia, pode evoluir para sepse, frequentemente necessita de antibioticoterapia de amplo espectro, bem como de várias abordagens cirúrgicas. Com o advento e acúmulo de evidências dos benefícios da terapia por pressão negativa (TPN), seu uso em alguns pacientes com FB tem sido relatado com resultados animadores relativos à sua viabilidade e ao seu custo-efetividade. O objetivo deste estudo foi demonstrar a aplicação de TPN como recurso para tratamento da FB e analisar comparativamente o custo global do seu tratamento.

Descritores: Fístula Brônquica. Pneumonectomia. Tratamento de Ferimentos com Pressão Negativa. Análise Custo-Benefício.

\section{REFERENCES}

1. Sarkar P, Chandak T, Shah R, Talwar A. Diagnosis and management bronchopleural fistula. Indian J Chest Dis Allied Sci. 2010;52(2):97-104.

2. Farina JA Jr, de Almeida CE, Marques EG, Jorge JL, Lima RV. Negative pressure wound therapy in grade IIIB tibial fractures: fewer infections and fewer flap procedures [letter]? Clin Orthop Relat Res. 2015;473(11):3682-3.

3. Coltro PS, Ferreira MC, Batista BP, Nakamoto HA, Milcheski DA, Tuma Júnior $P$. Role of plastic surgery on the treatment complex wounds. Rev Col Bras Cir. 2011;38(6):381-6.

4. Morodomi Y, Takenoyama M, Yamaguchi M, Inamasu E, Yoshida T, Kawano D, et al. Application of continuous negative pressure irrigation and negative pressure fixation to treat a bronchopleural fistula with thoracic empyema. J Am Coll Surg. 2014;218(5):e87-90.

5. Sziklavari Z, Grosser C, Neu R, Schemm R, Kortner A,
Szöke T, et al. Complex pleural empyema can be safely treated with vacuum-assisted closure. J Cardiothorac Surg. 2011;6:130

6. Omran N, Habal P, Mandak J, Chek JL. Broncho-pleural fistula following vacuum-assisted closure therapy. J Card Surg 2013;28(4):397-8.

7. Rocco G, Cecere C, La Rocca A, Martucci N, Salvi R, Passera $\mathrm{E}$, et al. Caveats in using vacuum-assisted closure for post-pneumonectomy empyema. Eur J Cardiothorac Surg. 2012;41(5):1069-71.

Received in: 29/02/2016

Accepted for publication: 09/06/2016

Conflict of interest: none.

Source of funding: none.

\section{Mailing address:}

Jayme Adriano Farina Junior

E-mail: jafarinajr@fmrp.usp.br 